\title{
Influence of food deprivation on intravenous glucose tolerance test traits in Holstein Friesian heifers
}

\author{
L. Antonio González-Grajales, ${ }^{*} \dagger$ Laura Pieper, ${ }^{*}{ }^{1}$ Joachim Kremer, ${ }^{*}$ and Rudolf Staufenbiel ${ }^{*}$ \\ ${ }^{*}$ Ruminant and Swine Clinic, Free University of Berlin, 14163 Berlin, Germany \\ †Technologie und Produktentwicklung Dr. Pieper GmbH, 16818 Wuthenow, Germany \\ łInstitute for Veterinary Epidemiology and Biostatistics, Free University of Berlin, 14163 Berlin, Germany
}

\begin{abstract}
Glucose is essential for numerous cellular functions due to its involvement in energy supply from early development to adulthood. In the lactating cow, glucose demands by the mammary gland significantly increase to support milk production when compared with other tissues. Thus, insufficient blood glucose levels might predispose dairy cows to metabolic disturbances. The intravenous glucose tolerance test (ivGTT) is a suitable tool to characterize glucose metabolism and insulin responses, but results must be reliable and repeatable. One factor influencing ivGTT is food deprivation period, which has been considered as an obligatory requirement before conduction of glucose tolerance studies in monogastric species, whereas it has been permissive in ruminants. The objective of this study was to determine the influence of 5 fasting periods $(0,12,24,36$, and 48 h) on ivGTT traits and insulin responses in German Holstein heifers. A total of 140 tests were conducted in 28 females aged 12 to 19 mo. Blood samples were collected every $7 \mathrm{~min}$ within $1 \mathrm{~h}$. Assessed glucose and insulin parameters included basal serum glucose and insulin concentration, maximum glucose and insulin concentration obtained between min 7 to 21 , and concentrations at min 63 (last sampling) relative to glucose administration, glucose area equivalent (GA), glucose area under the curve (GAUC), insulin area equivalent (InsA), insulin area under the curve (InsAUC), and blood glucose half-life time (GHLT). Serum glucose and insulin concentration were measured according to the hexokinase colorimetric method and solid phase radio immunoassay, respectively. The generalized linear mixed model was used to test for significant differences in all glucose traits and insulin responses at different fasting periods. The model used season and weight as confounding variables. Glucose and insulin concentrations at 0,7 to 21 (maximum concentration), and 63
\end{abstract}

Received October 10, 2016.

Accepted May 11, 2017.

${ }^{1}$ Corresponding author: laura.pieper@fu-berlin.de min were affected by the duration of food deprivation. The GA, InsA, GAUC, InsAUC, and especially GHLT were also affected by fasting period. A positive linear relationship between GHLT and length of food deprivation was found. Significantly higher GA, GAUC, GHLT values, and glucose and insulin concentration at min 63 were obtained at increasing fasting periods. High intraclass correlation coefficient (0.48) was found for GHLT. The results demonstrate that GHLT might be used to reliably characterize an individual's glucose metabolism and the importance of standardizing food deprivation schedules when performing an ivGTT in nongestating Holstein heifers.

Key words: metabolism, glucose tolerance test, glucose half-life time, fasting period

\section{INTRODUCTION}

Glucose metabolism has been extensively investigated in cattle due to its essential roles in numerous cellular processes. In dairy cows, balanced glucose metabolism is indispensable to ensure high milk yield, good fertility, and general health. Assessing the ability of an organism and its efficiency to properly secrete insulin and use glucose is commonly performed through an oral or intravenous glucose tolerance test (ivGTT) over a fixed period of time (Kaneko, 2008). The values derive from calculations denoting glucose half-life time (GHLT), glucose area equivalent (GA), and the rate at which the metabolite is cleared from the blood, among others (Freyer et al., 2004). In cattle, ivGTT is commonly used to test for conditions such as insulin resistance (De Koster and Opsomer, 2013) or determine the levels of insulin sensitivity (Abuelo et al., 2016). The test can also predict changes in nonesterified fatty acids (Boston et al., 2008) and determine the effects of certain diets on energy metabolism (Kneeskern et al., 2016). Furthermore, Pieper et al. (2016) found high heritability for some ivGTT traits in young Holstein bulls including GA and GHLT with estimated heritabilities of 0.43 and 0.40 , respectively. Therefore, altered glucose tolerance values could be linked to impaired metabolic responses 
at early stages, which could become an important selection criterion for animal health in the future. Other studies have proposed that glucose responses could predict the genetic ability for milk production in female calves (Sasaki et al., 2003) and heifers (Fiedorowicz et al., 2008).

Although the use of ivGTT in domestic cattle has generated significant advances in many fields, some factors (e.g., feed deprivation, glucose dose) influencing ivGTT traits have not fully been investigated. In monogastric species, food deprivation is crucial before sampling (Verkest et al., 2010) because high gluconeogenesis rates occur during the fasting phases (reviewed by Aschenbach et al., 2010). Conversely, numerous studies involving domestic cattle have omitted fasting periods, whereas others have implemented either food restriction during the examination or prolonged times. A summary of studies employing different fasting periods for ivGTT in female Holstein Friesian and other breeds during the last $10 \mathrm{yr}$ is provided in Tables 1 and 2 , respectively. The studies show diverse fasting periods ranging from 0 to $48 \mathrm{~h}$ and variations in glucose dose, which emphasizes the lack of standardization in domestic cattle.

Ruminants have a large number of phylogenetic particularities when compared with nonruminants. For instance, a large percentage of simple sugars and starch derived from the diet are used by ruminal microbes, whereas a small amount is able to pass to the small intestine (reviewed by Lean et al., 2014). It has been suggested that feeding does not cause a significant blood glucose response in adult cattle resulting in lack of necessity of fasting when performing an ivGTT (Kaneko, 2008). However, this hypothesis could lead to misinterpretation because previous studies have found significant differences in plasmatic concentrations of glucose, insulin, and other hormones in fasted lactating and nonlactating Holstein cows and heifers compared with nonfasted animals (Chelikani et al., 2004). Additionally, during the ruminal fermentation process, VFA are synthetized and subsequently used by the liver in a process known as gluconeogenesis (reviewed by Aschenbach et al., 2010). Therefore, alterations in feed intake might modify glucose and insulin concentration as demonstrated by some studies (Danfær, 1994). To our knowledge, no systematic investigation has addressed the effects of fasting period on ivGTT parameters. We hypothesized that ivGTT traits and insulin responses could vary depending on the length of food deprivation. The objective of this study was to determine the influence of 5 different fasting periods on ivGTT parameters in nonpregnant Holstein heifers.

\section{MATERIALS AND METHODS}

\section{Animals}

Twenty-eight nongestating Holstein Friesian heifers were obtained from a commercial dairy farm located in Northern Germany. At the beginning of the investigation, animals were 12 mo old with an average BW of 441.8 ( $\mathrm{SD}=3.5 \mathrm{~kg})$. Animals were kept in a freestall with headlocks on a rubber bedding surface.

\section{Study Design}

The tests were performed at the farm as a routine procedure. Animals were assigned to 5 groups in a crossover design study conducted during 2 seasons: (1) March to April and (2) October to November. Different animals

Table 1. Intravenous glucose tolerance test studies using different fasting periods in female Holstein Friesians in the last $10 \mathrm{yr}^{1}$

\begin{tabular}{|c|c|c|c|}
\hline $0.25 \mathrm{~g}$ of glucose $/ \mathrm{kg}$ of $\mathrm{BW}$ & 6 & $>2$ lactations & Abuelo et al. (2016) \\
\hline $150 \mathrm{mg} / \mathrm{kg}$ of BW (50\% dextrose sol) & 2 & $727 \mathrm{~kg}(22.3)$ & Hashemzadeh-Cigari et al. (2015) \\
\hline $1 \mathrm{~g}$ of glucose $/ \mathrm{kg}$ of $\mathrm{BW}^{0.75}$ & $\mathrm{OF}$ & $>2$ lactations & Hötger et al. (2013) \\
\hline $0.25 \mathrm{~g}$ of glucose $/ \mathrm{kg}$ of BW ( $50 \%$ dextrose sol) & 1 & NR & Tao et al. (2012) \\
\hline $0.25 \mathrm{~g}$ of glucose $/ \mathrm{kg}$ of BW ( $50 \%$ dextrose $\mathrm{sol})$ & 2 & 1.3 lactation $(0.6)$ & Huzzey et al. (2012) \\
\hline $50 \%$ dextrose sol & 0 & NR & Wheelock et al. (2010) \\
\hline $0.25 \mathrm{~g} / \mathrm{kg}$ of $\mathrm{BW}$ ( $50 \%$ dextrose sol) & $\mathrm{RF}$ & 671 (39) to $765 \mathrm{~kg}(36)$ & Pires et al. (2008) \\
\hline $0.3 \mathrm{~g} / \mathrm{kg}$ of BW (50\% D-glucose sol) & 12 & 2.5 lactations $(1.2)$ & Roche et al. (2008) \\
\hline $0.3 \mathrm{~g}$ of glucose $/ \mathrm{kg}$ of $\mathrm{BW}$ & 12 & $4.6 \mathrm{yr}(1.4)$ & Boston et al. (2008) \\
\hline $0.25 \mathrm{~g} / \mathrm{kg}$ of BW ( $50 \%$ dextrose sol) & $\mathrm{RF}$ & $786 \mathrm{~kg}(36)$ & Pires et al. (2007) \\
\hline $1.67 \mathrm{mmol}$ of glucose $/ \mathrm{kg}$ of BW ( $50 \%$ dextrose sol) & $\mathrm{RF}$ & $675 \mathrm{~kg}(69)$ & Bradford and Allen (2007) \\
\hline $0.45 \mathrm{~g} / \mathrm{kg}$ of $\mathrm{BW}^{0.75}$ & 1 & $11-14 \mathrm{mo}$ & Sumner et al. (2007) \\
\hline
\end{tabular}

${ }^{1}$ sol = solution; $\mathrm{NR}=$ not reported; $\mathrm{OF}=$ overnight fasting; $\mathrm{RF}=$ restricted feeding. 


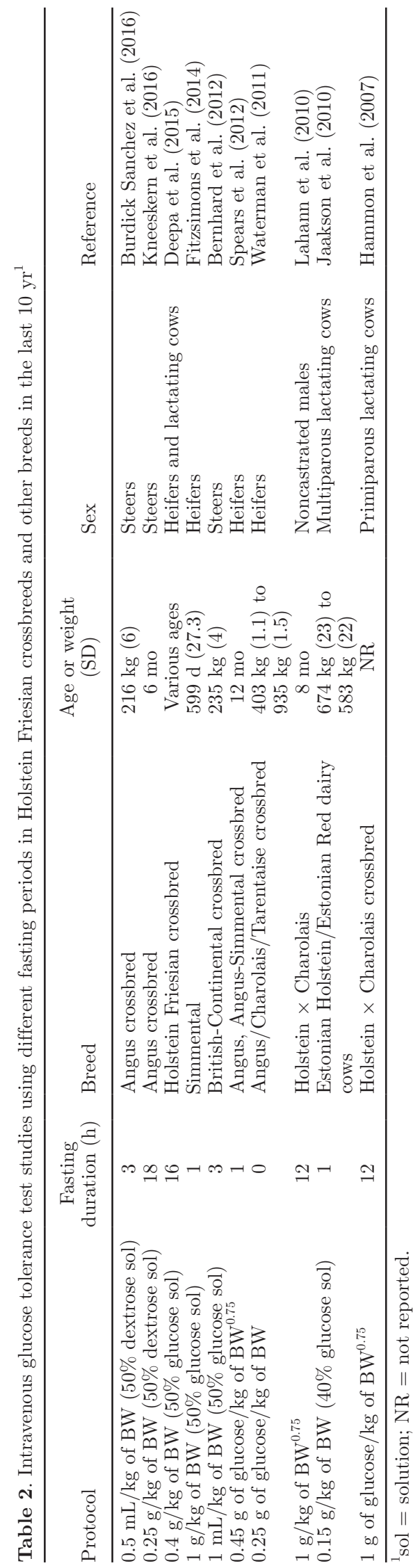

were enrolled during the 2 seasons. Fourteen heifers were used in season 1 and the remaining 14 in season 2 . Each individual was subjected to a total of 5 ivGTT (1 wk apart) including 5 different fasting periods (ad libitum feeding, 12, 24, 36, and $48 \mathrm{~h}$ ). Water was available at all times. A total of 140 tests were carried out. The protocols used in this study were approved and supervised by the Ethical Committee on animal welfare authority of Mecklenburg, Western Pomerania, Germany (protocol numbers LVL-M-V/310-4/72213-2.1-018/03 and LVL-M-V/310-4/72213-2.1-019/03).

\section{Intravenous Glucose Tolerance Test (ivGTT)}

Between 1 to $2 \mathrm{~h}$ before blood sampling, animals were weighed and tied. Additionally, an indwelling 14 gauge $\times 8 \mathrm{~cm}$ cannula Vasofix Braunüle (B Braun Melsungen AG, Melsungen, Germany) was inserted into a jugular vein and fixed to the skin with a single s.c. suture loop. After taking the first blood sample to determine basal glucose (G0) values, a $40 \%$ glucose solution (B Braun Vet Care, Melsungen AG, Melsungen, Germany) was warmed to $37^{\circ} \mathrm{C}$ and administered i.v. at $1 \mathrm{~g} / \mathrm{kg}$ of $\mathrm{BW}^{0.75}$. Glucose administration was performed with an automatic self-filling 10-mL syringe Vet-Matic (Henke Sass Wolf, Tuttlingen, Germany) and completed within 0.5 to 1 min after start of the injection. Thereafter, the catheter was flushed with $15 \mathrm{~mL}$ of $0.9 \% \mathrm{NaCl}$ solution (Isotone Kochsalz-Lösung, B Braun Melsungen AG) and blood samples were obtained at 7, 14, 21, 28, 35, 42, 49, 56 , and $63 \mathrm{~min}$ relative to the time of glucose injection. Samples were collected in 10-mL serum collection tubes (Kabe Labortechnik, Nümbrecht-Elsenroth, Germany) and centrifuged within 1 to $2 \mathrm{~h}$ postcollection at 2,000 $\times g$ for $10 \mathrm{~min}$ at $20^{\circ} \mathrm{C}$. Serum was stored at $-18^{\circ} \mathrm{C}$ until needed.

Serum glucose concentration was determined with the Gluco-quant Glucose/HK Cobas hexokinase test (Roche Diagnostics GmbH, Mannheim, Germany) according to the manufacturer's instructions using an automatic spectrophotometer analyzer (Cobas Mira Plus CC, Roche Diagnostics GmbH). Minimal detectable concentration for this method was at $0.11 \mathrm{mmol} / \mathrm{L}$. Insulin concentration was assessed by solid phase radioimmunoassay using a commercial kit (DPC Biermann GmbH, Bad Nauheim, Germany) as described by Kremer (2008). Analytical sensitivity was $1.2 \mu \mathrm{IU} /$ $\mathrm{mL}$ and coefficient of variation for this test ranged from 5.0 to $6.3 \%$ for intraassay precision and from 5.6 to $12.4 \%$ for interassay precision. Five ivGTT parameters and 4 insulin responses were included for analysis: G0, basal insulin concentration (Ins0), maximum glucose (GMAX) determined at min 7, maximum insulin concentration (InsMax) calculated between 14 to $21 \mathrm{~min}$ 
after i.v. injection, GHLT, GA, glucose area under the curve (GAUC), insulin area equivalent (InsA), insulin area under the curve (InsAUC), and glucose (G63) and insulin concentration (Ins63) at min 63. The GHLT was calculated as described by Kaneko (2008) using linear regression analysis of the natural logarithm of the glucose concentrations as follows:

$$
\operatorname{GHLT}=[\ln (2) / k] \times 100(\min ),
$$

The coefficient $(k)$ was calculated by the following formula:

$$
k=[\ln (\mathrm{G} 14)-\ln (\mathrm{G} 42)] /(\mathrm{T} 42-\mathrm{T} 14) \times 100(\% / \mathrm{min}),
$$

where G14 and G42 denote glucose concentrations at 14 and $42 \mathrm{~min}$ after glucose administration, respectively, whereas T42-T14 represents the time interval previously indicated. The GA, a parameter previously reported in other studies (Pieper et al., 2016), estimates the total area under the glucose curve as the sum of all glucose concentrations between 0 and $63 \mathrm{~min}$ after injection. The values are expressed without units. The trapezoidal rule was used to calculate GAUC and InsAUC to allow for comparison with current studies by other authors.

\section{Statistical Analysis}

Parameters derived from the glucose and insulin response curves were graphically analyzed for normality using histograms and normality tests (Shapiro-Wilk test). Data derived from all insulin responses except InsMax were not normally distributed, resulting in logarithmic transformation for further statistical analysis. Generalized linear mixed model was used to test for significant differences in ivGTT parameters and insulin responses among fasting treatments using season and weight as confounding variables and animal as a random effect (covariance structure $=$ variance components). Bonferroni test was selected to establish differences among groups. Residuals were assessed for outliers, homoscedasticity, and normality. The intraclass correlation coefficient (ICC) was calculated as indicated by Dohoo et al. (2009) and describes the correlation among observations from the same animal. For the variable G0, 2 values (one from 0 and $12 \mathrm{~h}$ fasting each) were excluded from the analysis due to extreme deviation from the remaining values (more than $2 \mathrm{SD}$ below other values from the same group). Other values from these animals appeared normal and observed deviations were likely due to analytical errors. Furthermore, Spearman correlation coefficient was used to determine the association between the duration of fasting and GHLT. The computer program SPSS Statistics version 22 (IBM Deutschland GmbH, Ehningen, Germany) was used and a $P$-value $<0.05$ was considered significant.

\section{RESULTS}

Changes in serum glucose and insulin concentrations following ivGTT at different fasting periods are shown in Figures 1 and 2. All ivGTT traits and insulin responses analyzed in this study were significantly affected $(P<0.01)$ by fasting periods (Tables 3 and 4 ). In the case of G0 and Ins0, the concentrations ranged from 3.8 to $4.5 \mathrm{mmol} / \mathrm{L}$ and 2.8 to $8.3 \mu \mathrm{IU} / \mathrm{mL}$, respectively (Tables 3 and 4). The G0 and Ins0 values were decreasing with increasing fasting periods $(P<$ 0.01). The GMAX and InsMax concentrations ranged from 13.6 to $14.7 \mathrm{mmol} / \mathrm{L}$ and 85.9 to $166.5 \mu \mathrm{IU} / \mathrm{mL}$, respectively. Significant differences for GMAX were only found between periods 0 and $36 \mathrm{~h}(P \leq 0.01)$, and $12 \mathrm{~h}$ compared with each 24,36 , and $48 \mathrm{~h}(P \leq$ 0.01). Insulin peak was achieved between 14 and $21 \mathrm{~min}$ after glucose injection. The G63 and Ins63 concentrations ranged from 4.40 to $6.73 \mathrm{mmol} / \mathrm{L}$ and 11.0 to $34.8 \mu \mathrm{IU} / \mathrm{mL}$, respectively (Tables 3 and 4 ), whereas GA and InsA ranged from 72.5 to 88.0 and 419.7 to 690.2, respectively. Values for G63, Ins63, GHLT, GA, and GAUC increased as the food deprivation times increased $(P<0.01)$. All GHLT values significantly differed among groups $(P<0.01)$, ranging from 27.6 to $52.3 \mathrm{~min}$. A positive correlation was observed between GHLT and length of deprivation time $(\mathrm{r}=0.80, P<$ $0.001, \mathrm{n}=140$ ). On average, there was a 6 min increase in GHLT per $12 \mathrm{~h}$ increase in fasting period (Table 3, Figure 3). The ICC was highest for GHLT (0.48) and lowest for G0 $(<0.01)$, and values for GMAX, G63, GA, and GAUC ranged between 0.14 and 0.26 (Table 3). The confounding factor season had a significant effect on almost all parameters studied (Tables 3 and $4 ; P<$ 0.05) except on G63, GHLT, or Ins0, with lower values observed in season 1. Conversely, BW had no effects on the parameters analyzed except for G0 whose values decreased by $0.02 \mathrm{mmol} / \mathrm{L}$ with a $10-\mathrm{kg}$ increase in $\mathrm{BW}$ $(P=0.02)$.

\section{DISCUSSION}

Glucose metabolism has become an important research field in ruminants due to its major role in many physiological stages such as pregnancy, growth, and lactation. Different tests have been used to measure an organism's response following glucose administration (Panicke et al., 2003). The ivGTT has been imple- 


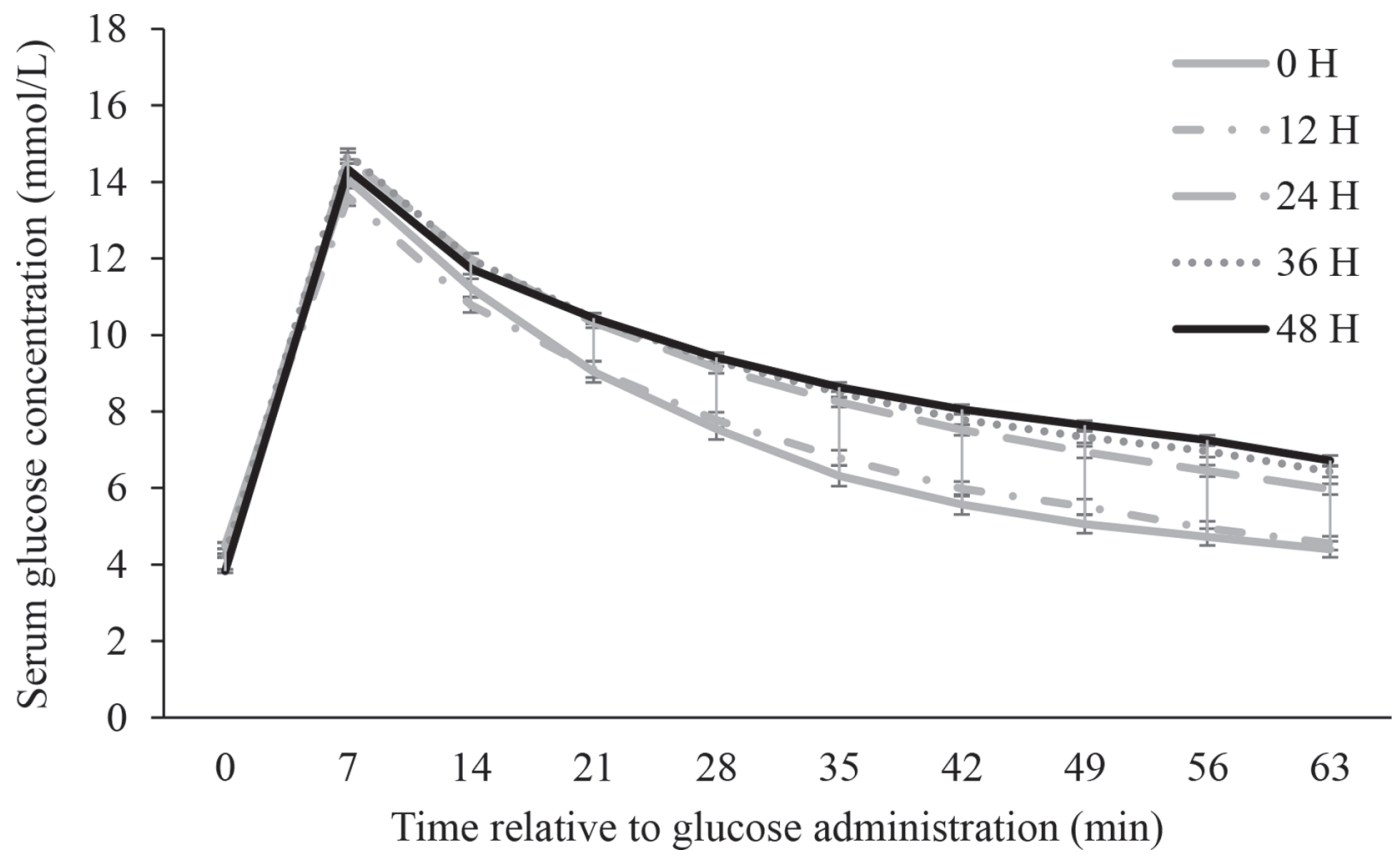

Figure 1. Mean blood serum glucose concentrations at different fasting periods $(0,12,24$, 36 , and $48 \mathrm{~h})$ obtained over $1 \mathrm{~h}$ after glucose injection. Bars indicate SEM.

mented extensively due to its practicality to calculate glucose turnover rates (Kaneko, 2008). However, factors influencing glucose metabolism before examination should be carefully reviewed to avoid misinterpretation. For instance, glucose metabolism in young calves con- trasts greatly from that in adults due to anatomical and physiological differences (Grütter and Blum, 1991). Lactating cows require higher amounts of carbohydrates to support milk synthesis compared with dry cows (van Dorland et al., 2009). Additionally, insulin

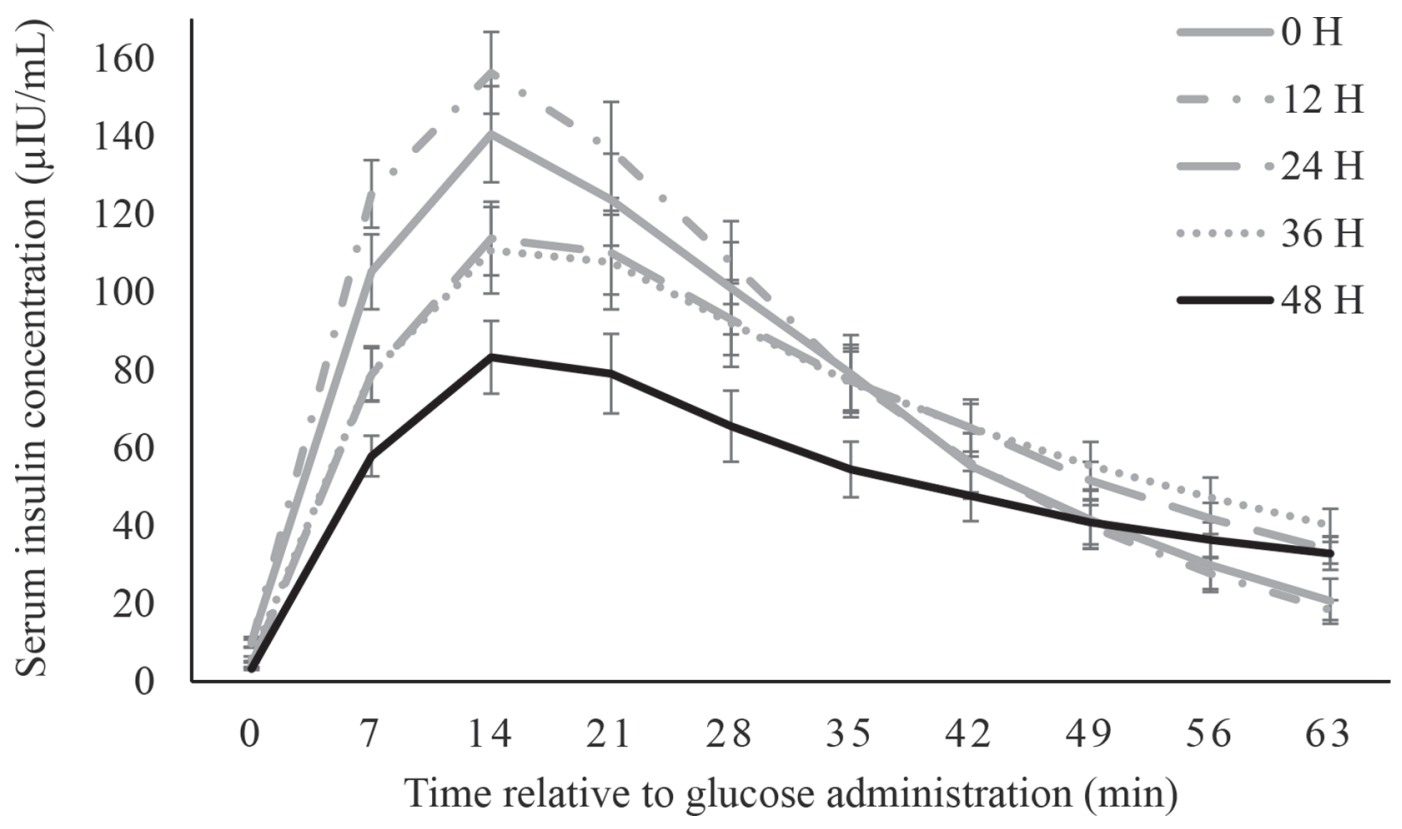

Figure 2. Mean blood serum insulin concentrations at different fasting periods $(0,12,24,36,48 \mathrm{~h})$ represented over $1 \mathrm{~h}$ after glucose administration. Bars indicate SEM. 
Table 3. Predicted means for intravenous glucose tolerance test (ivGTT) traits depending on fasting periods

\begin{tabular}{|c|c|c|c|c|c|c|c|}
\hline Item & $\mathrm{n}$ & \multicolumn{6}{|c|}{ 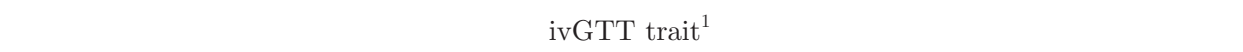 } \\
\hline \multicolumn{8}{|c|}{ Fasting period (h) } \\
\hline 0 & 28 & $4.55^{\mathrm{a}}$ & $14.1^{\mathrm{ab}}$ & $4.40^{\mathrm{a}}$ & $27.6^{\mathrm{a}}$ & $72.5^{\mathrm{a}}$ & $444.7^{\mathrm{a}}$ \\
\hline 12 & 28 & $4.50^{\mathrm{a}}$ & $13.6^{\mathrm{a}}$ & $4.56^{\mathrm{a}}$ & $33.8^{\mathrm{b}}$ & $73.6^{\mathrm{a}}$ & $450.6^{\mathrm{a}}$ \\
\hline 24 & 28 & $4.24^{\mathrm{b}}$ & $14.6^{\mathrm{bc}}$ & $5.97^{\mathrm{b}}$ & $42.7^{\mathrm{c}}$ & $85.5^{\mathrm{b}}$ & $519.1^{\mathrm{b}}$ \\
\hline \multicolumn{8}{|l|}{$P$-value } \\
\hline Time & & $<0.01$ & $<0.01$ & $<0.01$ & $<0.01$ & $<0.01$ & $<0.01$ \\
\hline Season & & $<0.01$ & 0.03 & 0.06 & 0.10 & $<0.01$ & $<0.01$ \\
\hline BW & & 0.02 & 0.17 & 0.8 & 0.36 & 0.74 & 0.65 \\
\hline $\mathrm{ICC}$ & & $<0.001$ & 0.14 & 0.24 & 0.48 & 0.26 & 0.26 \\
\hline
\end{tabular}

${ }^{\mathrm{a}-\mathrm{e}}$ Different letters indicate significant differences at $P<0.05$.

${ }^{1} \mathrm{G} 0=$ basal glucose concentration before infusion; GMAX = maximum increase in blood glucose concentration; G63 = glucose concentrations at 63 min after glucose injection; GHLT = glucose half-life time; GA = glucose area equivalent; GAUC = glucose area under the curve; ICC = intraclass correlation coefficient.

${ }^{2} \mathrm{G} 0$ values for fasting periods 0 and $12 \mathrm{~h}$ were estimated based on $\mathrm{n}=27$.

and glucose blood levels greatly differ depending on the physiological state (De Koster et al., 2017). During lactation, mammary epithelial cells express predominantly insulin-independent transporters for glucose uptake with lower glucose and insulin blood levels when compared with nonpregnant heifers, which exhibit higher glucose uptake through insulin-dependent transporters (Zhao and Keating, 2007). Other factors influencing the responses to an ivGTT include differences in glucose metabolism among breeds (Bossaert et al., 2009), and diet composition (Burgwald-Balstad et al., 1995). Our findings revealed that fasting influences all ivGTT traits and insulin responses. Longer deprivation times were characterized by increased GHLT values, and lower insulin responses (except Ins63) after glucose administration. The GHLT increased from 27.6 (0 h fasting period) to $52.3 \mathrm{~min}$ ( $48 \mathrm{~h}$ fasting period). Due to the linear relationship found between fasting periods and GHLT, researchers could easily adjust their expectations for GHLT when implementing ivGTT

Table 4. Predicted means for insulin responses depending on fasting periods

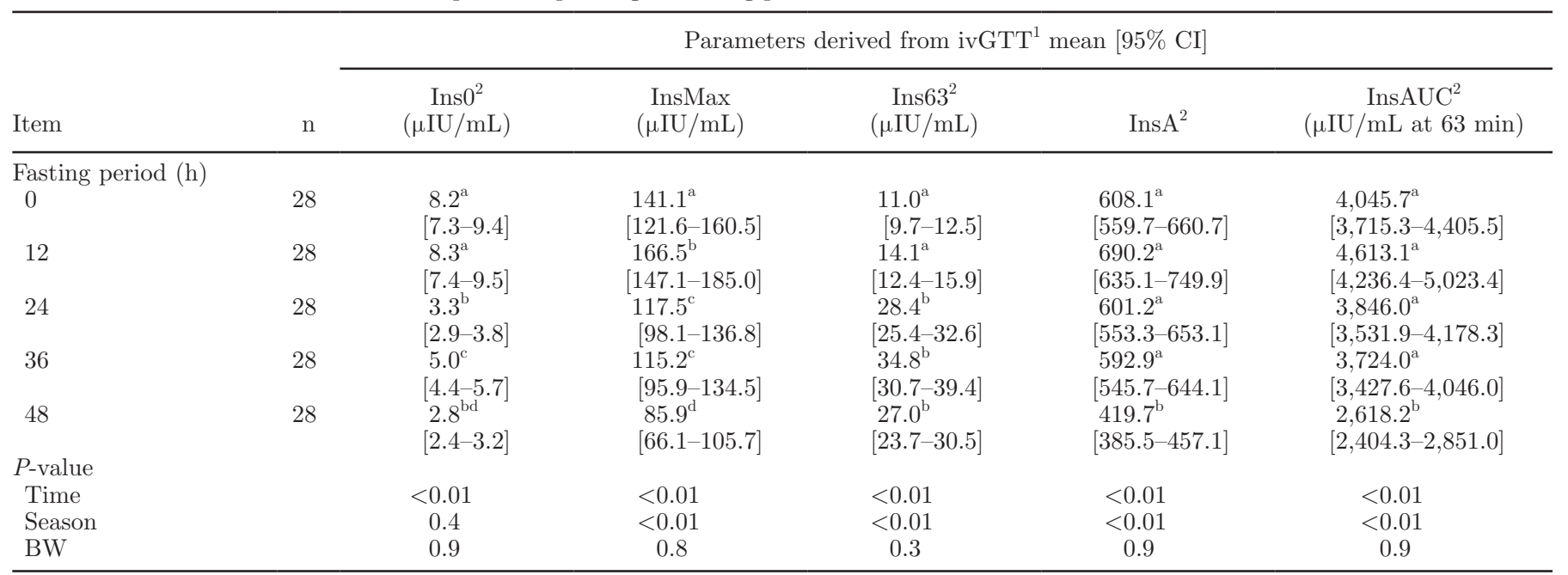

${ }^{\mathrm{a}-\mathrm{d}}$ Different letters indicate significant differences at $P<0.05$

${ }^{1}$ ivGTT $=$ intravenous glucose tolerance test; Ins $0=$ insulin basal concentration; InsMax $=$ insulin maximum concentration; Ins63 $=$ insulin concentration at $\min 63$; InsA $=$ insulin area equivalent; InsAUC $=$ insulin area under the curve.

${ }^{2}$ Values were back transformed to their original for representation. 
using various fasting periods. This is the first report investigating the influence of fasting period on ivGTT traits in nonpregnant Holstein-Friesian heifers.

Restricting feeding before conducting an ivGTT has received constant debate in cattle. It has been suggested that fasting periods are not a confounding factor when determining glucose curve concentrations in adult ruminants (Kaneko, 2008) due to limited intestinal glucose absorption (Reynolds et al., 1988). In vitro studies conducted in sheep have shown that liver cells derived from fed animals had higher glucose synthesis rates than cells cultured from fasted animals (Lomax et al., 1986). The results from our study demonstrate that basal glucose concentrations are affected by the length of fasting period, predominantly at 24,36 , and $48 \mathrm{~h}$. On the other hand, similar glucose concentrations were found when 12 -h food-deprived females were compared with animals without feed restriction, which might be attributed to the effects of rumen content on nutrient availability. These findings are in agreement with the study by Chelikani et al. (2004) that found a decrease in G0 concentrations by $17 \%$ in heifers $(16 \pm$ 0.3 mo old) when subjected to fasting between 12 and $48 \mathrm{~h}$. The same study showed significantly lower Ins0 in fasted (approximately $72 \mathrm{~h}$ ) Holstein heifers compared with the fed group and a $55 \%$ reduction in plasmatic concentration during the first $10 \mathrm{~h}$ of fasting. Their findings differ from our results because we were not able to identify differences in Ins0 between the group with ad libitum feeding and heifers fasted for $12 \mathrm{~h}$. Variations in dietary composition and quantity of OM at the time of blood collection might be attributable to the inconsistencies as reviewed by Harmon (1992).

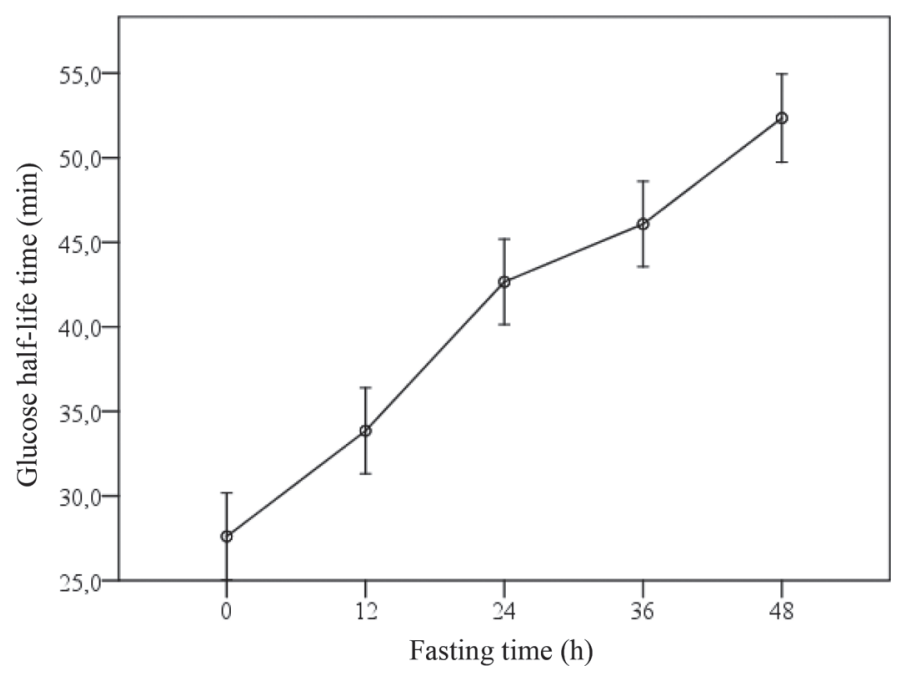

Figure 3. Linear relationship between mean glucose half-life time (GHLT) and 5 fasting periods. Bars indicate SEM.
It has been suggested that fasting could provoke slower glucose clearance due to depletion of insulin reserves (reviewed by van Meirhaeghe et al., 1988), resulting in increased GA, GAUC, G63, and GHLT as observed in our study. However, further studies should explore whether insulin secretion mechanisms, known in other species as the readily releasable pool and the reserve pool (reviewed by Bratanova-Tochkova et al., 2002), respond differently during prolonged fasting in heifers. In rodents, a positive correlation between the total number of insulin granules released by the readily releasable pool and the amount of insulin secreted during the first minutes after the glucose stimulus has been documented (Daniel et al., 1999). The lower values obtained for InsMax at increasing fasting periods in our study might be linked to altered insulin secretion-storage pathways due to less availability of primed insulin after prolonged fasting. Unfortunately, mechanisms regulating insulin and glucose metabolism are species dependent and progress in these areas has lagged in ruminants. The reduced tolerance for glucose at higher fasting periods observed in our study could also be explained by reduced expression of glucose transporters in insulin-dependent tissues. In rodent species, associations between fasting for $48 \mathrm{~h}$ and a significant reduction of mRNA expression and protein content of GLUT-4, an insulin-stimulated glucose uptake receptor, have been found (Camps et al., 1992; Zhao et al., 1993). Therefore, future cattle studies focusing on GLUT-4 downregulation might clarify our results regarding increased G63, Ins63, GAUC, and GHLT in nongestating heifers subjected to prolonged fasting.

Although evidence supports the influence of fasting on insulin and glucose plasmatic concentrations in dairy cattle (Chelikani et al., 2004), limited information is available about these effects in heifers. A study by Min et al. (1993) demonstrated that a 63-h fast provokes a steady decline in glucose concentration in Friesian calves at 3.5 and $7 \mathrm{mo}$ of age with significantly higher values in male calves at later ages. Early reports have also investigated the effects of a 48-h fast on GHLT in lactating adult cows and found significantly elevated GHLT in starved cows when compared with the control group (Hove, 1978). Marked differences in carbohydrate metabolism between lactating and nonlactating cattle have recently been attributed to glucose uptake by the mammary gland through insulin-independent pathways and lower glucose turnover rates in the former group (De Koster et al., 2017). Therefore, physiological differences are important factors that should be considered when analyzing GTT traits.

The influence of seasons on glucose metabolism has previously been investigated. In grazing cattle, a higher GHLT has been found in spring and summer. However, 
the degree of association varies depending on the nutrient density in forage rather than the season (Waterman et al., 2007). Similarly, our study found a significant influence of season on 4 ivGTT traits, a tendency for G63 and GHLT and almost all insulin responses with lower values observed during the spring. However, other studies have failed to identify this influence on G0 and GMAX during the spring compared with fall (Burkert, 1998). These disagreements are probably explained by study design, latitude, nutrient availability, management, and variations in environmental temperature, which in turn can affect plasmatic insulin concentration leading to decreased glucose turnover rates (Faulkner et al., 1980; Denbow et al., 1986). In beef cattle, differences in insulin maximum concentration and total insulin responses during the months of winter and spring have been observed (Waterman et al., 2007). Although these findings demonstrate the importance of accounting for confounding variables during experimental study design, the values must be interpreted cautiously because environmental conditions greatly differ among regions affecting the responsiveness of tissues to insulin.

Compared with other ivGTT traits, GHLT is highly dependent on the animal tested (high ICC value), which indicates that comparisons among different animals using various fasting periods are difficult. This supports the suitability of the cross over design used in our study. Moreover, GHLT is highly repeatable within an animal, whereas G0 values seem to be influenced by other factors besides individual variation. This is in agreement with a previous publication that showed a high heritability for GHLT and GA (Pieper et al., 2016). Despite the similar heritability values for both traits found by the authors, the results from our study reveal that GHLT would become a better indicator to assess genetic improvement of metabolic characteristics because higher ICC (0.48) was obtained when compared with GA (0.26). Therefore, ivGTT and specifically GHLT could be used as a potential measure for breeding selection and characterization of an individual glucose metabolism status in Holstein Friesian cattle with potential application for improved health.

The results from this study and recent evidence (Pieper et al., 2016) emphasize the usefulness of ivGTT to characterize glucose metabolism in Holstein Friesian heifers and bulls. Previous research conducted in our clinic showed that ivGTT could represent a valuable tool to select breeding bulls as an indicator of metabolic health due to the high heritability derived from GA and GHLT (0.43 vs. 0.40 ). However, our study revealed that GHLT would be preferred over other ivGTT traits due to higher repeatability. In addition to these findings, our study confirms that the length of fasting significantly altered all ivGTT traits and insulin responses. Thus, it is imperative to consider fasting as a modulating factor in glucose metabolism when designing experiments involving dairy cattle. Consequently, comparable results among studies might be obtained by standardization of glucose dose and fasting period, among others. It would be recommended to use a minimum fasting period of $12 \mathrm{~h}$ as a standardized time for subsequent examinations in nonpregnant Holstein heifers because almost no analyzed ivGTT traits differed between 0 - and 12 -h fasting periods (except for GHLT and InsMax). The suggested time is practical because animals could be food deprived only during one night, which might reduce fasting-associated stress commonly manifested as frequent vocalizations and anxiety. However, the implemented time before conduction of ivGTT would depend on feasibility and objectives of the research study.

\section{CONCLUSIONS}

Despite the metabolic particularities between ruminants and monogastric animals, the results from our study demonstrate that variations in the length of food deprivation before performing an ivGTT alter not only basal glucose concentrations but also all ivGTT traits and insulin responses. Decreased glucose tolerance determined by longer GHLT and higher GA denote the effect of different fasting schedules on glucose metabolism. Our findings also evidenced the importance of standardizing the test using a 12-h food deprivation period in nongestational heifers. Researchers interested in implementing ivGTT should always be aware of the effect of fasting periods on ruminant glucose metabolism.

\section{ACKNOWLEDGMENTS}

The authors thank Sebastian Mengel (Ruminant and Swine Clinic, Free University of Berlin, Berlin, Germany) for assisting the sample collections and Michaela Waberowski (Ruminant and Swine Clinic, Free University of Berlin) for supporting laboratory analysis. This study was partially funded by Technologie und Produktentwicklung Dr. Pieper GmbH, Wuthenow, Germany.

\section{REFERENCES}

Abuelo, A., V. Alves-Nores, J. Hernandez, R. Muiño, J. L. Benedito, and C. Castillo. 2016. Effect of parenteral antioxidant supplementation during the dry period on postpartum glucose tolerance in dairy cows. J. Vet. Intern. Med. 30:892-898.

Aschenbach, J. R., N. B. Kristensen, S. S. Donkin, H. M. Hammon, and G. B. Penner. 2010. Gluconeogenesis in dairy cows: The secret of making sweet milk from sour dough. IUBMB Life 62:869-877.

Bernhard, B. C., N. C. Burdick, R. J. Rathmann, J. A. Carroll, D. N. Finck, M. A. Jennings, T. R. Young, and B. J. Johnson. 2012. Chromium supplementation alters both glucose and lipid metabo- 
lism in feedlot cattle during the receiving period. J. Anim. Sci. 90:4857-4865.

Bossaert, P., J. L. M. R. Leroy, S. De Campeneere, S. De Vliegher, and G. Opsomer. 2009. Differences in the glucose-induced insulin response and the peripheral insulin responsiveness between neonatal calves of the Belgian Blue, Holstein-Friesian, and East Flemish breeds. J. Dairy Sci. 92:4404-4411.

Boston, R. C., J. R. Roche, G. M. Ward, and P. J. Moate. 2008. A novel minimal model to describe non-esterified fatty acid kinetics in Holstein dairy cows. J. Dairy Res. 75:13-18.

Bradford, B. J., and M. S. Allen. 2007. Depression in feed intake by a highly fermentable diet is related to plasma insulin concentration and insulin response to glucose infusion. J. Dairy Sci. 90:38383845 .

Bratanova-Tochkova, T. K., H. Cheng, S. Daniel, S. Gunawardana Y.-J. Liu, J. Mulvaney-Musa, T. Schermerhorn, S. G. Straub, H. Yajima, and G. W. G. Sharp. 2002. Triggering and augmentation mechanisms, granule pools, and biphasic insulin secretion. Diabetes 51(Suppl. 1):S83-S90.

Burdick Sanchez, N. C., J. A. Carroll, P. R. Broadway, H. D. Hughes, S. L. Roberts, J. T. Richeson, T. B. Schmidt, and R. C. Vann. 2016. Cattle temperament influences metabolism: Metabolic response to glucose tolerance and insulin sensitivity tests in beef steers. Domest. Anim. Endocrinol. 56:85-95.

Burgwald-Balstad, L. A., J. S. Caton, V. I. Burke, and K. C. Olson 1995. Influence of forage level and naloxone injection on feed intake, digestion, and plasma hormone and metabolite concentrations in dairy heifers. J. Anim. Sci. 73:2677-2686.

Burkert, O. 1998. Investigation about the intravenous and modified glucose tolerance test in breeding bulls [in German with English abstract]. Doctoral dissertation, Ruminant and Swine Clinic, Free Univ., Berlin, Germany.

Camps, M., A. Castelló, P. Muñoz, M. Monfar, X. Testar, M. Palacín, and A. Zorzano. 1992. Effect of diabetes and fasting on GLUT4 (muscle/fat) glucose-transporter expression in insulin-sensitive tissues. Heterogeneous response in heart, red and white muscle. Biochem. J. 282:765-772.

Chagas, L. M., F. M. Rhodes, D. Blache, P. J. S. Gore, K. A. Macdonald, and G. A. Verkerk. 2006. Precalving effects on metabolic responses and postpartum anestrus in grazing primiparous dairy cows. J. Dairy Sci. 89:1981-1989.

Chelikani, P. K., J. D. Ambrose, D. H. Keisler, and J. J. Kennelly. 2004. Effect of short-term fasting on plasma concentrations of leptin and other hormones and metabolites in dairy cattle. Domest. Anim. Endocrinol. 26:33-48.

Danfær, A. 1994. Nutrient metabolism and utilization in the liver. Livest. Prod. Sci. 39:115-127.

Daniel, S., M. Noda, S. G. Straub, and G. W. Sharp. 1999. Identification of the docked granule pool responsible for the first phase of glucose-stimulated insulin secretion. Diabetes 48:1686-1690.

De Koster, J., M. Van Eetvelde, K. Hermans, W. Van den Broeck, M. Hostens, and G. Opsomer. 2017. Short communication: Limitations of glucose tolerance tests in the assessment of peripheral tissue insulin sensitivity during pregnancy and lactation in dairy heifers. J. Dairy Sci. 100:2381-2387.

De Koster, J. D., and G. Opsomer. 2013. Insulin resistance in dairy cows. Vet. Clin. North Am. Food Anim. Pract. 29:299-322.

Deepa, P. M., U. Dimri, R. Jhambh, M. I. Yatoo, and B. Sharma. 2015. Alteration in clinico-biochemical profile and oxidative stress indices associated with hyperglycaemia with special reference to diabetes in cattle - A pilot study. Trop. Anim. Health Prod. 47:103-109.

Denbow, C. J., K. S. Perera, F. C. Gwazdauskas, R. M. Akers, R. E. Pearson, and M. L. McGilliard. 1986. Effect of season and stage of lactation on plasma insulin and glucose following glucose injection in Holstein cattle. J. Dairy Sci. 69:211-216.

Dohoo, I. R., W. Martin, and H. Stryhn. 2009. Veterinary Epidemiologic Research. 2nd ed. VER Inc., Charlottetown, Canada.

Faulkner, A., E. M. Thomson, J. M. Bassett, and G. E. Thomsont. 1980. Cold exposure and mammary glucose metabolism in the lactating goat. Br. J. Nutr. 43:163-170.
Fiedorowicz, S., N. Strzałkowska, E. Bagnicka, A. Józ'wik, J. Krzyżewski, and Z. Reklewski. 2008. Relationship between certain parameters included in the glucose tolerance test in young heifers and their milk production traits in forthcoming lactation. Anim. Sci. Pap. Rep. 26:97-105.

Fitzsimons, C., D. A. Kenny, S. M. Waters, B. Earley, and M. McGee. 2014. Effects of phenotypic residual feed intake on response to a glucose tolerance test and gene expression in the insulin signaling pathway in longissimus dorsi in beef cattle. J. Anim. Sci. 92:4616-4631.

Freyer, G., R. Staufenbiel, E. Fisher, and L. Panicke. 2004. Parameters of glucose tolerance test traits in dairy cattle. Arch.Tierz. 49:120-132.

Grütter, R., and J. Blum. 1991. Insulin and glucose in neonatal calves after peroral insulin and intravenous glucose administration. Reprod. Nutr. Dev. 31:389-397.

Hammon, H. M., O. Bellmann, J. Voigt, F. Schneider, and C. Kühn. 2007. Glucose-dependent insulin response and milk production in heifers within a segregating resource family population. J. Dairy Sci. 90:3247-3254.

Harmon, D. L. 1992. Impact of nutrition on pancreatic exocrine and endocrine secretion in ruminants: A review. J. Anim. Sci. 70:12901301

Hashemzadeh-Cigari, F., G. R. Ghorbani, M. Khorvash, A. Riasi, A. Taghizadeh, and Q. Zebeli. 2015. Supplementation of herbal plants differently modulated metabolic profile, insulin sensitivity, and oxidative stress in transition dairy cows fed various extruded oil seeds. Prev. Vet. Med. 118:45-55.

Hötger, K., H. M. Hammon, C. Weber, S. Görs, A. Tröscher, R. M Bruckmaier, and C. C. Metges. 2013. Supplementation of conjugated linoleic acid in dairy cows reduces endogenous glucose production during early lactation. J. Dairy Sci. 96:2258-2270.

Hove, K. 1978. Insulin secretion in lactating cows: Responses to glucose infused intravenously in normal, ketonemic, and starved animals. J. Dairy Sci. 61:1407-1413.

Huzzey, J. M., R. J. Grant, and T. R. Overton. 2012. Short communication: Relationship between competitive success during displacements at an overstocked feed bunk and measures of physiology and behavior in Holstein dairy cattle. J. Dairy Sci. 95:4434-4441.

Jaakson, H., K. Ling, J. Samarütel, A. Ilves, T. Kaart, and O. Kärt. 2010. Field trial on glucose-induced insulin and metabolite responses in Estonian Holstein and Estonian Red dairy cows in two herds. Acta Vet. Scand. 52:4-7.

Kaneko, J. J. 2008. Carbohydrate metabolism and its diseases. Pages 45-80 in Clinical Biochemistry of Domestic Animals. 6th ed. J. J. Kaneko, W. J. Harvey, and L. M. Bruss, ed. Academic Press, San Diego, CA.

Kneeskern, S. G., A. C. Dilger, S. C. Loerch, D. W. Shike, and T. L. Felix. 2016. Effects of chromium supplementation to feedlot steers on growth performance, insulin sensitivity, and carcass characteristics. J. Anim. Sci. 94:217-226.

Kremer, J. 2008. Einfluss der Dauer der Nüchternzeit auf das Ergebnis im intravenösen Glukosetoleranztest beim weiblichen Jungrind [in German with English abstract]. Doctoral dissertation, Ruminant and Swine Clinic, Free Univ., Berlin, Germany.

Lahann, P., J. Voigt, C. Kühn, R. Pfuhl, C. C. Metges, P. Junghans, U. Schönhusen, and H. M. Hammon. 2010. Energy expenditure, urea kinetics, and body weight gain within a segregating resource family population. J. Dairy Sci. 93:5118-5128.

Lean, I. J., H. M. Golder, and M. B. Hall. 2014. Feeding, evaluating, and controlling rumen function. Vet. Clin. North Am. Food Anim. Pract. 30:539-575.

Lohrenz, A. K., K. Duske, F. Schneider, K. Nürnberg, B. Losand, H. M. Seyfert, C. C. Metges, and H. M. Hammon. 2010. Milk performance and glucose metabolism in dairy cows fed rumen-protected fat during mid lactation. J. Dairy Sci. 93:5867-5876.

Lomax, M. A., I. A. Donaldson, and C. I. Pogson. 1986. The effect of fatty acids and starvation on the metabolism of gluconeogenic precursors by isolated sheep liver cells. Biochem. J. 240:277-280.

Marett, L. C., M. J. Auldist, P. J. Moate, W. J. Wales, K. L. Macmillan, F. R. Dunshea, and B. J. Leury. 2015. Response of plasma glu- 
cose, insulin, and nonesterified fatty acids to intravenous glucose tolerance tests in dairy cows during a 670-day lactation. J. Dairy Sci. 98:179-189.

Min, S. H., S. N. McCutcheon, D. D. S. Mackenzie, and B. W. Wickham. 1993. Plasma metabolite and hormone concentrations in Friesian calves of low and high genetic merit: Effects of sex and age. Anim. Prod. 56:17-27.

Panicke, L., U. Müller, H. Behn, R. Staufenbiel, and A. Oprzadek. 2003. Metabolic traits and the metabolic status by heifers in the glucose tolerance test. Page 263 in Proc. 54th Annual Meeting of the EAAP. Wageningen Academic Publishers, Rome, Italy.

Pieper, L., R. Staufenbiel, J. Christ, L. Panicke, U. Müller, and G. A. Brockmann. 2016. Heritability of metabolic response to the intravenous glucose tolerance test in German Holstein Friesian bulls. J. Dairy Sci. 99:7240-7246.

Pires, J. A. A., J. B. Pescara, A. E. Brickner, N. Silva del Rio, A. P. Cunha, and R. R. Grummer. 2008. Effects of abomasal infusion of linseed oil on responses to glucose and insulin in Holstein cows. J. Dairy Sci. 91:1378-1390.

Pires, J. A. A., J. B. Pescara, and R. R. Grummer. 2007. Reduction of plasma NEFA concentration by nicotinic acid enhances the response to insulin in feed-restricted Holstein cows. J. Dairy Sci. 90:4635-4642.

Reynolds, C. K., G. B. Huntington, H. F. Tyrrell, and P. J. Reynolds. 1988. Net portal-drained visceral and hepatic metabolism of glucose, L-lactate, and nitrogenous compounds in lactating Holstein cows. J. Dairy Sci. 71:1803-1812.

Roche, J. R., A. J. Sheahan, L. M. Chagas, and R. C. Boston. 2008. Short communication: Change in plasma ghrelin in dairy cows following an intravenous glucose challenge. J. Dairy Sci. 91:10051010 .

Sasaki, O., N. Yamamoto, K. Togashi, M. Minezawa, K. Ishii, and H. Takeda. 2003. Use of plasma metabolite concentrations after glucose injection to predict the genetic ability of milk production in young calves. Jpn. Agric. Res. Q. 37:133-140.

Schoenberg, K. M., R. M. Ehrhardt, and T. R. Overton. 2012. Effects of plane of nutrition and feed deprivation on insulin responses in dairy cattle during late gestation. J. Dairy Sci. 95:670-682.

Spears, J. W., C. S. Whisnant, G. B. Huntington, K. E. Lloyd, R. S. Fry, K. Krafka, A. Lamptey, and J. Hyda. 2012. Chromium pro- pionate enhances insulin sensitivity in growing cattle. J. Dairy Sci. 95:2037-2045.

Sumner, J. M., F. Valdez, and J. P. McNamara. 2007. Effects of chromium propionate on response to an intravenous glucose tolerance test in growing Holstein heifers. J. Dairy Sci. 90:3467-3474.

Tao, S., I. M. Thompson, A. P. A. Monteiro, M. J. Hayen, L. J. Young, and G. E. Dahl. 2012. Effect of cooling heat-stressed dairy cows during the dry period on insulin response. J. Dairy Sci. 95:50355046.

van Dorland, H. A., S. Richter, I. Morel, M. G. Doherr, N. Castro, and R. M. Bruckmaier. 2009. Variation in hepatic regulation of metabolism during the dry period and in early lactation in dairy cows. J. Dairy Sci. 92:1924-1940.

van Meirhaeghe, H., P. Deprez, C. Vandenhende, and E. Muylle. 1988. Plasma-glucose clearance and insulin-response in cows with abomasal displacement. Zentralbl. Veterinarmed. A 35:221-228.

Verkest, K. R., L. M. Fleeman, J. S. Rand, and J. M. Morton. 2010 Basal measures of insulin sensitivity and insulin secretion and simplified glucose tolerance tests in dogs. Domest. Anim. Endocrinol. 39:194-204.

Waterman, R. C., E. E. Grings, T. W. Geary, A. J. Roberts, L. J. Alexander, and M. D. MacNeil. 2007. Influence of seasonal forage quality on glucose kinetics of young beef cows. J. Anim. Sci. $85: 2582-2595$.

Waterman, R. C., A. J. Roberts, T. W. Geary, E. E. Grings, L. J. Alexander, and M. D. MacNeil. 2011. Effect of reduced heifer nutrition during in utero and post-weaning development on glucose and acetate kinetics. Br. J. Nutr. 106:1702-1712.

Wheelock, J. B., R. P. Rhoads, M. J. VanBaale, S. R. Sanders, and L. H. Baumgard. 2010. Effects of heat stress on energetic metabolism in lactating Holstein cows. J. Dairy Sci. 93:644-655.

Zhao, F. Q., D. R. Glimm, and J. J. Kennelly. 1993. Distribution of mammalian facilitative glucose transporter messenger RNA in bovine tissues. Int. J. Biochem. 25:1897-1903.

Zhao, F. Q., and A. F. Keating. 2007. Expression and regulation of glucose transporters in the bovine mammary gland. J. Dairy Sci. 90(Suppl. 1):E76-E86. 